In view of these experiences, we would urge the College to debate these issues and to seek clarification of the role of managers tribunals vis-áa-vis the MHARTs in the discharge of detained patients.

P. POWER-SMITH

M. Evans

The Yews

Worrall Road

Sheffield S30 $3 A U$

See also letter from Anne Farmer and Mark Winston; Psychiatric Bulletin, 1992, 16, 567568-eds.

\section{Current operation of Mental Health Review Tribunals}

DeAR SIRS

We have been commissioned by the Department of Health to carry out a one year study of current practices regarding the operation of Mental Health Review Tribunals, with a particular emphasis on patterns of delay. Over the next few months we will be contacting a random sample of general and forensic psychiatrists to ask for their views. However, we would be most grateful to hear from any member of the College who has views on this subject, and in particular for decreasing the length of time it takes to obtain a tribunal hearing. These views will influence both the nature of our study, and its conclusions. All views will, however, be received in strict confidence.

Finally, the study is only concerning the current situation in England.

STEPHEN BLUMENTHAL SIMON WESSELY

Academic Department of Psychological Medicine King's Healthcare

King's College Hospital

Denmark Hill

London SE5 9RS

\section{Interpretation of the Mental Health Act}

DeAr Sirs

There has been much correspondence recently concerning the interpretation of the Mental Health Act. It seems that even with guidelines there are still situations where interpretation of the Act is difficult.

A number of scenarios appear to cause particular problems, some involving differences of opinion between psychiatrists and social workers; for instance, a conflict between psychiatrists wishing to recommend a Section 3 Treatment Order for a patients whom they know well while the social worker may wish to use a Section 2 Assessment Order as being 'the least restrictive alternative'.
I would suggest that detailed case vignettes are devised and that the Mental Health Act Commission produce recommended guidelines as to how the Act should be interpreted in these cases. This should help the situation that can occur when there is an honest disagreement between disciplines as to correct management.

Leicester General Hospital

TREVOR FriedMaN

Leicester LE5 4PW

\section{Prospective refusals of health authorities to fund psychiatric admissions}

DeAR SiRS

Many colleagues may have received a clinical description of a patient of a health authority in south eastern England accompanied by a letter from that health authority refusing to fund any admission to a psychiatric bed without prior consultation with the patient's consultant. This is being circulated as a strictly confidential document. There are two aspects of this exercise that have caused me concern.

The first concern I have is entirely selfish but it should not be expected of me as a duty psychiatrist to bear in mind a list of the names of patients of other health authorities who should not be admitted to hospital on the basis of my judgement alone.

The second concern is an inevitable consequence of this exercise. For it to be effective it has been necessary to circulate the name and clinical description of the patient to every district health authority with a request that the information be circulated to all appropriate psychiatric units. In order for this to be then implementable the information must go either to the treasurer of all units or to every doctor who may be on-call to grant or refuse admission to a unit. I think such an exercise can hardly be described as strictly confidential.

I can well appreciate that health authorities need to try and keep some control over their liabilities but I really do think that this requires a rather wider debate before further exercises of this kind take place.

\section{Campbell Centre}

Philip Strangeway

\section{The Hospital Campus \\ Eaglestone}

Milton Keynes MK6 5NG

\section{Self-audit: benefits in training and clinical practice}

\section{DeAR SiRS}

The monitoring and evaluation processes of audit were applied to the activities of a registrar during a 